\title{
Price Risk and Risk Management in Agriculture
}

\author{
Udo Broll ${ }^{1}$, Peter Welzel ${ }^{2}$, Kit Pong Wong ${ }^{3}$
}

ABSTRACT

\begin{abstract}
This note studies the risk-management decisions of a risk-averse farmer. The farmer faces multiple sources of price uncertainty. He sells commodities to two markets at two prices, but only one of these markets has a futures market. We show that the farmer's optimal commodity futures market position, i.e., a cross-hedge strategy, is actually an over-hedge, a full-hedge, or an under-hedge strategy, depending on whether the two prices are strongly positively correlated, uncorrelated, or negatively correlated, respectively.
\end{abstract}

KEY WORDS: $\quad$ agricultural price risk; risk management; commodity futures; correlation; cross-hedge

JEL Classification: $\quad$ D73, D78, D83

${ }^{1}$ Technische Universität Dresden, Germany; ${ }^{2}$ University of Augsburg, Germany; ${ }^{3}$ University of Hong Kong, Hong Kong

\section{Introduction}

In today's economy, farmers and agribusiness firms face a high degree of risk because of certain new factors, such as the increased price volatility of inputs and outputs, climate change, international trade restrictions, new and more stringent food safety standards, and greater public concern about the environment, to name only a few. These developments coincide with major changes in the fundamentals of the agriculture market (UNCTAD, 2011). A critical issue in agriculture is adjusting supply and price risk. The role of economic risk is particularly important for pricing in commodity futures markets. In developed economies, farmers have access to commodity futures markets in which they can hedge the price risk.

Since 2006, there have been significant price fluctuations in major food commodities on international markets. Between early 2006 and mid-2008, grain and

Correspondence concerning this article should be addressed to: Udo Broll, Technische Universität Dresden, 01062 Dresden, Germany, e-mail: udo.broll@tu-dresden.de cereal prices more than doubled in real terms before falling sharply during the second half of 2008. From 2010 through 2012, prices again increased rapidly and generated fears that the global market was entering a phase of sustained commodity price volatility. Although short-term coping strategies are important particularly in economies that are negatively affected by rising food prices (Prakash, 2011; Prakash, \& Gilbert, 2011) - an important part of the economic policy debate addresses the question of whether these recent price fluctuations are the result of speculation in the futures markets or whether they simply reflect the underlying economic fundamentals.

However, futures markets in the real world are far from complete. For example, less-developed countries and economies in transition - places in which risksharing markets are embryonic and markets are heavily controlled - are unlikely to have futures markets for agricultural goods. Farmers that are exposed to commodity price uncertainty must therefore rely on commodity futures contracts on related goods to indirectly hedge against their price-risk exposure (Allen and Lu- 
eck, 2003; UNCTAD, 2011). Such a risk-management technique is referred to as cross hedging (see, e.g., Anderson and Danthine, 1981; Broll, Wong, \& Zilcha, 1999; Chang, \& Wong, 2003; Frechette, 2000; Haigh, \& Holt, 2000; Hudson, 2007). An important part of the policy debate in agriculture addresses the question of whether commodity price volatility results from speculation in the futures market or whether it simply reflects the underlying economic fundamentals (e.g., Gilbert, 2010; Food and Agriculture Organization [FAO], 2011; Ziegler, 2012). In this context, there is growing concern that financial investment into commodity derivatives may have become an independent source of price behavior and is causing the recent volatility.

The purpose of this note is to provide theoretical insights into optimal cross-hedging strategies for farmers' contracts. To that end, we consider a riskaverse farmer who sells his output to two markets; however, only one of these markets has a futures market to which the farmer has access. We show that the farmer's optimal futures position hinges on the bivariate dependence of the random commodity prices in the separate markets. To derive concrete results, we propose the concepts of strong correlation. We show that the farmer can find an optimal solution through over-hedging, full-hedging, or under-hedging strategies, depending on whether the two random prices are strongly positively correlated, uncorrelated, or negatively uncorrelated, respectively.

The rest of this note is organized as follows. The next section develops the model of a farmer facing price risk and cross-hedging opportunities, and the section following that describes the farmer's optimal commodity futures hedging strategy. The final section concludes.

\section{The Model}

We consider a farmer who produces two final outputs, indexed by $i=1$ and 2. Let $x_{i}$ and $p_{i}$ be the amount of outputs and the per-unit selling commodity price in market $i$, where $i=1$ and 2. Profit risk comes from two sources, $\widetilde{p}_{1}$ and $\widetilde{p}_{2}$, which denote the pricing of the random goods in markets 1 and 2 , respectively (the tilde $(\sim)$ denotes a random variable). Cross hedging is modeled by allowing the farmer to trade infinitely divisible futures contracts in the market for the first good at the forward rate, denoted by $p_{1}^{f}$. There are no direct hedging instruments for the random price of the second good, $\widetilde{p}_{2}$.

The farmer's profits are given by

$\widetilde{\Pi}=\widetilde{p}_{1} x_{1}+\widetilde{p}_{2} x_{2}+\left(p_{1}^{f}-\widetilde{p}_{1}\right) h$,

where $h$ is the number of futures contracts sold (purchased, if negative). The farmer is risk averse and possesses a von Neumann-Morgenstern utility function, $U(\Pi)$, which is defined over its profits, $\Pi$, with $U^{\prime}(\Pi)>0$ and $U^{\prime \prime}(\Pi)<0$. For a given production, the farmer's decision problem is to choose his futures market position, $h$, to maximize the expected utility of its profits

$\max _{h} \mathrm{E}[U(\widetilde{\Pi})]$

where $\mathrm{E}(\cdot)$ is the expectation operator. The first-order condition for program (2) is given by

$\mathrm{E}\left[U^{\prime}\left(\widetilde{\Pi}^{*}\right)\left(p_{1}^{f}-\widetilde{p}_{1}\right)\right]=0$,

where an asterisk $\left({ }^{*}\right)$ indicates an optimal level. Given the assumed properties of $U(\Pi)$, the second-order condition for program (2) is satisfied.

\section{Optimal Risk Management Policy}

To examine the farmer's optimal futures position, $h^{*}$, we write equation (3) as

$\mathrm{E}\left[U^{\prime}\left(\widetilde{\Pi}^{*}\right)\right]\left[p_{1}^{f}-\mathrm{E}\left(\widetilde{p}_{1}\right)\right]-\operatorname{cov}\left[U^{\prime}\left(\widetilde{\Pi}^{*}\right), \widetilde{e}_{1}\right]=0$,

where $\operatorname{cov}(\cdot, \cdot)$ is the covariance operator. (Please note that for any two random variables, $\tilde{x}$ and $\tilde{y}$, we have $\operatorname{cov}(\tilde{x}, \tilde{y})=\mathrm{E}(\tilde{x} \tilde{y})-\mathrm{E}(\tilde{x}) \mathrm{E}(\tilde{y})$.$) Evaluating the left-$ hand side of equation (4) at $h^{*}=x_{1}$ yields

$\left.\mathrm{E}\left\{U^{\prime}\left[p_{1}^{f} x_{1}+\widetilde{p}_{2} x_{2}\right)\right]\right\}\left[p_{1}^{f}-\mathrm{E}\left(\widetilde{p}_{1}\right)\right]+$

$-\operatorname{cov}\left\{U^{\prime}\left[p_{1}^{f} x_{1}+\tilde{p}_{2} x_{2}\right], \tilde{p}_{1}\right\}$.

If the above expression is positive, zero, or negative, equation (4) and the strict concavity of $\mathrm{E}\left[U^{\prime}(\widetilde{\Pi})\right]$ imply that $h^{*}$ is greater than, equal to, or less than $x_{1}$, respectively.

It is impossible to determine the sign of expression (5) without imposing concepts of bivariate dependence upon $\widetilde{p}_{1}$ and $\widetilde{p}_{2}$. Thus, we offer the following definition. 
Definition: The random variable, $\tilde{x}$, is said to be strongly positively correlated, uncorrelated, or negatively correlated to the random variable, $\tilde{y}$, if, and only if, $\operatorname{cov}[\tilde{x}, f(\tilde{y})]$ is positive, zero, or negative, respectively, for all strictly increasing functions, $f(\cdot)$.

This definition is motivated by similarly ordered random variables in Hardy, Littlewood, and Pólya (1934) and Ingersoll (1987). An example of strongly correlated random variables is the following linear specification: $\tilde{p}_{2}=\alpha+\beta \widetilde{p}_{1}+\widetilde{\varepsilon}$, where $\alpha$ and $\beta$ are scalars, and $\widetilde{\varepsilon}$ is a zero-mean random variable independent of $\tilde{p}_{1}$. This linear specification is widely used in the hedging literature.

Result 1: Given that the farmer is allowed to trade commodity futures contracts, if $\widetilde{p}_{1}$ and $\widetilde{p}_{2}$ are strongly uncorrelated, then the farmer's optimal future position, $h^{*}$, is greater than, equal to, or less than $x_{1}$, depending on whether $p_{1}^{f}$ is greater than, equal to, or less than $\mathrm{E}\left(\widetilde{p}_{1}\right)$, respectively. If $\widetilde{p}_{1}$ and $\widetilde{p}_{2}$ are strongly positively (negatively) correlated, then the farmer's optimal future position, $h^{*}$, is greater (less) than $x_{1}$, when $p_{1}^{f} \geq(\leq) \mathrm{E}\left(\tilde{p}_{1}\right)$

Proof: If $\tilde{p}_{1}$ and $\tilde{p}_{2}$ are strongly uncorrelated, then the covariance term of expression (5) vanishes. Thus, expression (5) is positive, zero, or negative, depending on whether $p_{1}^{f}$ is greater than, equal to, or less than $\mathrm{E}\left(\tilde{p}_{1}\right)$, respectively, which implies that $h^{*}$ is greater than, equal to, or less than $x_{1}$, respectively.

If $\tilde{p}_{1}$ and $\tilde{p}_{2}$ are strongly positively (negatively) correlated, then the covariance term of expression (5) is positive (negative). Thus, expression (5) is positive (negative) when $p_{1}^{f} \geq(\leq) \mathrm{E}\left(\tilde{p}_{1}\right)$, such that $h^{*}>(<) x_{1}$.

The logic of Result 1 may be shown as follows. Considering the variance on both sides of equation (1), we have

$$
\begin{aligned}
& \operatorname{var}(\widetilde{\Pi})=\operatorname{var}\left(\widetilde{p}_{1}\right)\left(x_{1}-h\right)^{2}+\operatorname{var}\left(\widetilde{p}_{2}\right) x_{2}^{2}+ \\
& +2 \operatorname{cov}\left(\widetilde{p}_{1}, \widetilde{p}_{2}\right)\left(x_{1}-h\right) x_{2}
\end{aligned}
$$

where var $(\cdot)$ is the variance operator. Partially differentiating equation (6) with respect to $h$ and evaluating the resulting derivative at $h=x_{1}$ yields

$$
\left.\frac{\partial}{\partial h} \operatorname{var}(\widetilde{\Pi})\right|_{h=x_{1}}=-2 \operatorname{cov}\left(\tilde{p}_{1}, \tilde{p}_{2}\right) x_{2} .
$$

If $\tilde{p}_{1}$ and $\tilde{p}_{2}$ are strongly positively (negatively) correlated, we have $\operatorname{cov}\left(\tilde{p}_{1}, \tilde{p}_{2}\right)>(<) 0$. According to equation (7), the farmer finds it optimal to set $h>(<) x_{1}$ to reduce the variability of its profits. When $p_{1}^{f}>(<) \mathrm{E}\left(\tilde{p}_{1}\right)$, a speculative motivation may induce the farmer to sell (purchase) forward contracts. Thus, the over-hedging (under-hedging) incentive for risk minimization is reinforced by speculative motivations when $p_{1}^{f} \geq(\leq) \mathrm{E}\left(\tilde{p}_{1}\right)$.

If $\tilde{p}_{1}$ and $\tilde{p}_{2}$ are strongly uncorrelated, we have $\operatorname{cov}\left(\tilde{p}_{1}, \tilde{p}_{2}\right)=0$. Thus, equation (7) implies that $h=x_{1}$ minimizes the variability of the farmer's domestic profits. The farmer deviates from this full hedge only when $p_{1}^{f} \neq \mathrm{E}\left(\tilde{p}_{1}\right)$. If $p_{1}^{f}>(<) \mathrm{E}\left(\tilde{p}_{1}\right)$, speculative motivations induce the farmer to sell (purchase) forward contracts, thereby making the over-hedging (underhedging) strategy optimal.

\section{Conclusion}

In today's economy, farmers and agribusiness firms face a high degree of risk because of certain new factors, such as greater price volatility for inputs and outputs, climate change, international trade restrictions, and new and more stringent food safety standards. These developments coincide with major changes in the fundamentals of the agriculture market. A critical issue in agriculture is price risk.

An important topic in the policy debate in agriculture concerns the question of whether the volatility in commodity prices results from speculation in the futures market or whether this volatility simply reflects the underlying economic fundamentals. In this context, there is growing concern that financial investment into commodity derivatives based on the replication of futures indices has become an independent source of price behavior and is causing recent patterns of price volatility in these markets.

In this note, we have examined the optimal riskmanagement decisions of a risk-averse farmer who is facing multiple sources of commodity price uncertainty. The farmer sells commodities to two markets, but only one of these has a futures market. We have shown that the farmer's optimal forward position is an over-hedge, a full-hedge, or an under-hedge strategy, depending on whether the two random commodity prices are strongly positively correlated, uncorrelated, or negatively correlated, respectively. 


\section{References}

Allen, D. W., Lueck, D. (2003). The Nature of the Farm: Contracts, Risk and Organizsation in Agriculture. Cambridge, MA: MIT Press.

Anderson, R. W., Danthine, J.-P. (1981). Cross Hedging. Journal of Political Economy, 89(6), 1182-1196.

Broll, U., Wong, K. P., \& Zilcha, I. (1999). Multiple Currencies and Hedging. Economica, 66(264), 421-432.

Chang, E. C., Wong, K. P. (2003). Cross-Hedging with Currency Options and Futures. Journal of Financial and Quantitative Analysis, 38(3), 555-574.

Food and Agriculture Organization (2011, June 2). Price Volatility in Food and Agricultural Markets: Policy Responses. Retrieved from: http://www. globalbioenergy.org/uploads/media/1106_FAO_ et_al._-_Price_volatility_in_food_and_agricultural_markets_policy_responses_.pdf

Frechette, D. L. (2000). The Demand for Hedging and the Value of Hedging Opportunities. American Journal of Agricultural Economics, 82(4), 897-907.

Gilbert, C. L. (2010). How to Understand High Food Prices. Journal of Agricultural Economics, 61(2), 398-425.

Haigh M. S. Holt, M. T. (2000). Hedging Multiple Price Uncertainty in International Grain Trade. American Agricultural Journal of Economics, 82(4), 881-896.

Hardy, G. H., Littlewood, J. E., Pólya, G. (1934). Inequalities. London, UK: Cambridge University Press.

Hudson, D. (2007). Agricultural Markets and Prices. Malden, MA: Blackwell.

Ingersoll, J. E. Jr. (1987). Theory of Financial Decision Making. Savage, MD: Rowman and Littlefield.

Prakash, A. (2011). Why Volatility Matters. In A. Prakash (Ed.), Safeguarding Food Security in Volatile Global Markets (pp. 1-24). Rome: FAO.

Prakash, A., Gilbert, C. L. (2011). Rising Vulnerability in the Global Food System: Beyond Market Fundamentals. In A. Prakash (Ed.), Safeguarding Food Security in Volatile Global Markets (pp. 45-66), Rome: FAO.

UNCTAD. (2011). Price Information in Financialized Commodity Markets: The Role of Information. New York, NY: United Nations Publication. Retrieved from http://unctad.org/en/Docs/ gds20111_en.pdf
Ziegler, J. (2012). Wir lassen Sie verhungern. Muenchen: Bertelsmann. 